\title{
PENGARUH CAPITAL ADEQUACY RATIO, INFLASI, DAN GROSS DOMESTIC PRODUCT TERHADAP RETURN ON ASSETS (STUDI PADA BANK UMUM SYARIAH NON DEVISA DI INDONESIA PERIODE TAHUN 2018-2020)
}

\author{
Lutfi Indriwati ${ }^{1}$, Agung Eko Purwana ${ }^{2}$ \\ ${ }^{1,2}$ Institut Agama islam Negeri Ponorogo, Indonesia \\ Email : luthfiindri@gmail.com ${ }^{1}$
}

\begin{abstract}
This research examines the influence of CAR, inflation and GDP on ROA of Non-Foreign Exchange Sharia Commercial Banks in Indonesia. In the research period there were cases in the financial statements where CAR increased but ROA decreased, in addition when inflation decreased ROA also decreased and at the time of GDP rise ROA again decreased. The novelty of this research is a method of regression of panel data that has never been used in CAR, inflation and GDP together. This research is quantitative with a sample number of 4 Non-Foreign Exchange Sharia Commercial Banks. The findings in this study are that CAR, inflation and GDP have no partial effect on ROA. However, CAR, inflation, and GDP simultaneously affect ROA. The next research is expected to take variables other than CAR, inflation, and GDP that theoretically affect roa of Non-Foreign Exchange Sharia Commercial Banks in order to obtain a better roa model of Non-Foreign Exchange Sharia Commercial Banks compared to this study.
\end{abstract}

Keywords: Income, Economic Growth, Capital, Investment

Abstrak: Riset ini menguji pengaruh CAR, inflasi dan GDP terhadap ROA Bank Umum Syariah Non Devisa di Indonesia. Pada periode riset ditemui kasus pada laporan keuangan dimana CAR mengalami peningkatan namun ROA mengalami penurunan, selain itu ketika inflasi mengalami penurunan ROA turut mengalami penurunan serta pada saat GDP naik ROA kembali mengalami penurunan. Kebaruan dari riset ini berupa metode regresi data panel yang belum pernah digunakan pada CAR, inflasi dan GDP secara bersama. Riset ini berjenis kuantitatif dengan jumlah sampel 4 Bank Umum Syariah Non Devisa. Temuan pada riset ini adalah CAR, inflasi dan GDP secara parsial tidak berpengaruh pada ROA. Namun, CAR, inflasi, serta GDP secara simultan berpengaruh pada ROA. Riset berikutnya diharapkan dapat mengambil variabel lain selain CAR, inflasi, dan GDP yang secara teori berpengaruh pada ROA Bank Umum Syariah Non Devisa agar diperoleh model ROA Bank Umum Syariah Non Devisa yang lebih baik dibandingkan dengan penelitian ini.

Kata Kunci : Pendapatan, Pertumbuhan Ekonomi, Modal, Investasi 


\section{PENDAHULUAN}

Bank mempunyai kedudukan berarti dalam perekonomian yang berperan selaku pengumpul serta penyalur aset publik. Selain itu, Bank bermaksud menolong penerapan kemajuan publik untuk membangun nilai, pengembangan keuangan serta kekuatan publik mengarah kenaikan rakyat banyak (Hasibuan, 2001). Pada tahun 1970-an, bank yang bekerja dengan standar syariah Islam mulai tumbuh pesat di dunia. Pemulihan kualitas yang krusial sudah melahirkan Islamisasi bidang moneter dengan penekanan pada perbankan tanpa bunga (free interest banking) ataupun biasanya diketahui dengan sebutan perbankan Islam ataupun perbankan syariah.

Semakin berkembangnya Bank Syariah di Indonesia mengakibatkan penyajian bank syariah harus ditingkatkan agar pengelolaan perbankan dengan standar syariah dapat dijalankan dengan sehat dan tetap sasaran. Return On Assets(ROA) memiliki arti penting untuk bank karena menunjukkan nilai manfaat atau keuntungan dari bank. Semakin besar keuntungan dari sumber daya yang dimiliki bank maka semakin penting tingkat manfaat yang dicapai bank tersebut serta semakin baik bank dalam menggunakan sumber daya. ROA yang rendah memperlihatkan rendahnya kemampuan bank dalam mengawasi kontribusi modal dalam menghasilkan keuntungan (Mawaddah, 2015).

Beberapa faktor yang bisa pengaruhi ROA bank menurut Pandia antara lain Size, Capital Adequacy Ratio(CAR), Non Performing Loan(NPL), Net Interest Margin(NIM), Serta Loan To Deposit Ratio (LDR) (Loraine Pertiwi, 2019). Menurut Balanchandher, keuntungan yang diporeh bank dapat dipengaruhi oleh faktor didalam menejemen maupun faktor diluar manajemen. Faktor didalam manajemen merupakan faktor yang dapat dikendalikan oleh manajemen yang berupa kebijakan serta keputusan manajemen bank dalam hal penyimpan dana, manajemen modal, manajemen likuiditas, serta manajemen biaya. Faktor diluar manejemen merupakan faktor yang tidak dapat dikendalikan yaitu faktor lingkungan meliputi struktur pasar, regulasi, inflasi, tingkatan suku bunga, serta Produk Domestik Bruto (Hidayati A. N., 2014). Berdasarkan beberapa faktor yang berpengaruh pada ROA, pada riset ini difokuskan pada variabel Capital Adequacy Ratio(CAR), Inflasi serta Gross Domestic Product (GDP) sebagai faktor yang mempengaruhi ROA.

Capital Adequacy Ratio (CAR) dapat memberikan pengaruh pada tingkatan pengembalian sumber daya (ROA) bank syariah. Menurut Dendawijaya, CAR merupakan proporsi yang digunakan dalam mengukur kecukupan modal yang dimiliki 
bank untuk memberikan bantuan yang memiliki atau memunculkan resiko (pemberian kredit). Bank yang ada di Indonesia diwajibkan untuk memberikan 8\% dari ATMR sebagai modal dasar (Rihfenti Ernayani, 2017). Menurut Yuliani serta Azwir, CAR mempunyai manfaat yang besar pada ROA. Ketika CAR mengalami peningkatan ROA juga mengalami peningkatan (Edhi Satriyo Wibowo, 2013).

Tidak hanya permasalahan manajemen modal (CAR) yang mempengarhui bank syariah, inflasi yang besar turut memberikan pengaruh pada bank syariah. Inflasi menggambarkan peningkatan harga barang serta jasa dalam perekonomian pada periode waktu tertentu. Inflasi yang tinggi mengakibatkan biaya tenaga tenaga kerja serta produk dalam perekonomian ikut tinggi (Hidayati A. N., 2014). Tingginya inflasi ini berbanding terbalik dengan ROA yang dapat diartikan sebagai semakin tinggi inflasi maka semakin rendah ROA. Faktor yang berpengaruh pada ROA selanjutnya adalah Gross Domestic Product (GDP) ataupun Produk Domestik Bruto. GDP dipandang sebagai nilai pasar dari seluruh jasa maupun barang jadi dihasilkan dalam periode waktu tertentu di suatu Negara. Perkembangan GDP di suatu Negara memberikan pengaruh pada perolehan laba dari sumber daya bank. Sahara menyatakan bahwa GDP memperikan pengaruh pada ROA. Ketika GDP naik maka ROA akan naik. (I Nyoman Sidhi Adiyadnya, 2017).

Bersumber pada pemaparan diatas, riset ini dilakukan untuk mendapatkan faktor yang memberikan pengaruh pada ROA Bank Umum Syariah Non Devisa di Indonesia sehingga dapat dijadikan bahan masukan oleh manajemen Bank Umum Syariah Non Devisa untuk dapat meningkatkan ROA yang dimiliki.

\section{TINJAUAN LITERATUR}

\section{Return On Assets}

Return On Assets (ROA) ialah rasio yang menampilkan hasil atas jumlah aktiva yang dipakai dalam industri (Kasmir, 2014). Rasio ROA didapatkan dengan membagi segala laba yang didapatkan oleh bank (saat sebelum pajak) dengan seluruh asset bank tersebut. ROA yang tinggi memperlihatkan bahwa bank memiliki kinerja keuanganyang tinggi karena bank mampu menghasilkan tingkat pengembalian yang besar. (Santoso, 1997).

ROA dipakai manjemen industri untuk menilai ketepatan seluruh operasi yang ada pada industry tersebut. ROA dipakai untuk mengukur kinerja keuangan banyak industri multinasional yang dilihat dari sudut pandang profitabilitas dan peluang investasi 
(Husna, 1998). ROA dapat digunakan untuk mengenali hubungan antara organisasi serta kinerja keuangan bank-bank retail untuk dapat menuyusun strategi dalam menghadapi persaingan yang semakin ketat. Bank Indonesia lebih mengedepankan nilai profitabilitas bank yang diukur melalui asset yang sebagian besar dananya diperoleh dari simpanan masyarakat (Siamat, 2005). Bank Indonesia menetapkan suatu bank dalam keadaan sehat ketika bank tersebut memiliki rasio ROA minimun 1,5\%. Untuk menghitung ROA dapat menggunakan rumus berikut: (Alim, 2013)

$$
\frac{\text { Laba Sebelum Pajak }}{\text { Total Aset }} \times 100 \%
$$

\section{Capital Adequacy Ratio}

Capital Adequacy Ratio(CAR) disebut juga rasio kecukupan permodalan adalah modal dasar yang harus dipenuhi oleh bank. CAR menunjukkan besarnya jumlah aktiva yang mengandung atau berpotensi mengakibatkan resiko (kredit, penyertaan, pesan berharga, tagihan, pada bank lain) ikut dibiayai dari modal yang dimiliki oleh bank. $C A R$ menampilkan seberapa besar penyusutan asset bank yang masih bisa ditutup oleh equity bank yang ada.

CAR merupakan perbandingan dari modal sendiri bank dengan kebutuhan modal yang tersedia setelah dihitung perkembangan resiko (margin risk) dari akibat yang berisiko (Sinungan, 1993). Menurut Suhardi, teknis kewajiban penyediaan modal minimum dapat dinilai dari persentase tertentu terhadap Aktiva Tertimbang Bagi Resiko( ATMR) dimana modal meliputi modal inti serta modal pelengkap (Suhardi, 2003).

Nilai CAR sesuai syarat Bank Indonesia merupakan sebesar 8\%, ini berarti bank tersebut sanggup membiayai operasi bank. Keadaan yang menguntungkan bank tersebut akan membagikan donasi yang lumayan besar untuk Return On Assets. Pesan Edaran Bank Indonesia No 6/ 23/ DPNP bertepatan pada 31 Mei 2004 Capital Adequacy Ratio diformulasikan sebagai berikut (Harun, 2016):

$$
C A R=\frac{\text { Total Modal }}{\text { ATMR }} \times 100 \%
$$

\section{Inflasi}

Menurut R. McConnell Campbell dan Stanley L Brue mengemukakan inflasi adalah $a$ rise in the general tingkat of price (Brue, 1990). Inflasi adalah meningkatnya 
harga barang atau komoditas serta jasa secara umum selama periode waktu tertentu. Menurut Adiwarman A. Karim inflasi islam tidak berbeda dengan inflasi konvensional (Karim, 2004).

Adrian Sutedi menyatakan bahwa indikator inflasi terdiri dari Indeks Harga Konsumen (IHK) serta Indeks Harga Perdagangan Besar (IHPB). IHK adalah indikator digunakan untuk memvisualisasikan harga. Pergeseran IHK memperlihatkan adanya pergeseran harga barang maupun jasa yang dikonsumsi oleh masyarakat dari waktu ke waktu. IHPB adalah indicator yang dapat digunakan untuk memvisualisasikan pergeseran harga dari komoditas yang diperdagangkan pada suatu daerah (Suted, 2012).

Inflasi menurut Al-Maqrizi Taqyudin disebabkan oleh Natural Inflation dan Human Error Inflation. Inflasi berdampak pada tidak dapat berfungsinya uang sebagai satuan hitung yang adil dan benar. Selain itu, inflasi dapat menyebabkan redistribusi pendapatan dan kekayaan, salah satunya adalah redistribusi dari kreditur ke debitur.

\section{Gross Domestic Product}

Gross Domestic Product (GDP) atau yang biasa disebut sebagai Produk Domestik Bruto(PDB) adalah konsep yang paling penting jika dibandingkan dengan konsep pendapatan nasional lainnya. GDP adalah nilai dari barang maupun jasa yang diproduksi selama periode waktu tertentu di suatu negara (Suryanto, 2000). GDP meliputi output barang maupun jasa dalam suatu perekonomian yang dimilik Negara maupun warga Negara asing yang berdomisili di Negara tersebut. Sebagai contoh, di Indonesia ada suatu perusahaan yang milik oleh penduduk inggris, maka penghasilan yang diperoleh oleh perusahaan tersebut merupakan bagian dari GDP Indonesia. GDP dapat dihitung menggunakan rumus berikut:

$$
\mathbf{Y}=\mathbf{C}+\mathbf{G}+\mathbf{I}+(\mathbf{X}-\mathbf{M})
$$

GPD terdiri dari pendekatan produksi (Value Added Approach), pendekatan pendapatan (Income Approach/Earning Approach), maupun pendekatan pengeluaran (Expenditure Approach). Pendekatan produksi didefinisikan sebagai nilai tambah yang dibuat dalam proses produksi. Pendekatan Pendapatan merupakan pendekatan yang mengarah pada penerimaan yang diperoleh dari faktor-faktor produksi. Pendekatan Pengeluaran merupakan pendekatan yang mengarah kepada pengeluaran pada sektor ekonomi suatu negara. 


\section{METODE PENELITIAN}

Pendekatan kuantitatif digunakan pada riset ini dengan metode analisis regresi data panel. Riset ini terdiri dari tiga variabel bebas (CAR, inflasi, dan GDP) serta satu variabel terikat (ROA). Data yang dipakai merupakan data triwulan yang diperoleh dari laporan keuangan Bank Umum Syariah Non Devisa periode tahun 2018-2020 yang diterbitkan oleh Otoritas Jasa Keuagan serta dari Bank Indonesia.

Metode pengambilan sampling dilakukan melakukan pertimbangan sesuai dengan tujuan penelitian (purposive sampling). Berdasarkan metode tersebut, sampel pada riset ini adalah Bank Umum Syariah Non Devisa yang terdiri dari Bank BRISyariah, Bank Syariah Bukopin, Bank Victoria Syariah serta Bank Jabar Banten Syariah.

Langkah-langkah analisis pada riset ini meliputi analisis deskriptif, Regresi Data Panel, Uji Asumsi Klasik, Uji Parsial (Uji t), Uji Simultan (Uji F) serta Koefisien Determinasi $\left(\mathrm{R}^{2}\right)$. Model regresi data panel pada riset ini sebagai berikut(Sriyana, 2014):

$$
Y i t=ß 0 i+\beta 1 X 1 i t+\beta 2 X 2 i t+\beta 3 X 3 i t+e i t
$$

\section{HASIL DAN PEMBAHASAN}

\section{Uji Statistik Deskriptif}

Tabel 1. Hasil Pengujian Deskriptif

\begin{tabular}{cccccc}
\hline Variabel & $\mathrm{N}$ & $\begin{array}{c}\text { Rata-rata } \\
(\%)\end{array}$ & Maks $(\%)$ & Min $(\%)$ & $\begin{array}{c}\text { Deviasi Standar } \\
(\%)\end{array}$ \\
\hline ROA & 40 & 0,35 & 1 & 0,02 & 0,27 \\
\hline CAR & 40 & 20,17 & 30,07 & 14,45 & 4,53 \\
\hline Inflasi & 40 & 2,93 & 3,44 & 1,96 & 0,43 \\
\hline GDP & 40 & 4,26 & 5,27 & $-1,26$ & 1,97
\end{tabular}

Sumber : Data diolah (2021)

Tabel 1 memperlihatkan hasil perhitungan jumlah sampel, rata-rata, maksimum, minimum dan deviasi standar. Hasil perhitungan menunjukkan bahwa ROA memiliki nilai rata-rata 0,35 dengan deviasi standar 0,27. Nilai deviasi standar dari ROA paling kecil dibandingkan dengan variabel lainnya yang artinya ROA memiliki nilai paling homogen dibandingkan dengan variabel lainnya. Variabel CAR dengan nilai rata-rata 20,17 dan deviasi standar 4,53 menunjukkan bahwa nilai CAR memiliki tingkat keragaman yang tinggi dan nilainya cenderung bervariasi. 


\section{Pengujian Regresi Data Panel}

Model regresi data panel meliputi model common effect, fixed effect, dan random effects. Untuk mendapatkan model regresi data panel yang paling sesuai digunakan uji Chow serta uji Hausman. Uji chow adalah uji yang digunakan untuk menentukan model yang paling sesuai antara model common effect dan fixed effect sedangkan uji hausman merupakan uji yang dipakai untuk memilih model yang paling sesuai antara model fixed effects dan model random effects

Pada uji Chow, nilai signifikansi yang diperoleh pada pengujian tersebut dibandingkan dengan $\alpha=0,05$ dengan kriteria jika nilai signifikansi>0,05 maka model common effect merupakan model yang paling sesuai dan sebaliknya jika nilai signifikansi<0,05 maka model fixed effect merupakan paling sesuai.

Tabel 2. Hasil Uji Chow

\begin{tabular}{cccc}
\hline Effects Test & Stat & df & Sig \\
\hline Cross-section F & 17,418492 & $(3,33)$ & 0,0000 \\
\hline Cross-section $\chi^{2}$ & 37,965791 & 3 & 0,0000 \\
\hline
\end{tabular}

Sumber: Data diolah (2021)

Tabel 3. Hasil Uji Hausman

\begin{tabular}{cccc}
\hline Test Summary & $\chi^{2}$ & df & Sig \\
\hline Cross-section random & 14,153931 & 3 & 0,0027 \\
\hline
\end{tabular}

Sumber: Data diolah (2021)

Hasil uji Chow pada Tabel 2 memperlihatkan nilai sig=0,000 kurang dari 0,05 sehingga model yang sesuai adalah model fixed effects. Setelah diperoleh model fixed effect dilanjutkan dengan uji hausman. Pada uji Hausman, nilai signifikansi yang diperoleh pada pengujian tersebut dibandingkan dengan nilai $\alpha$ dengan kriteria jika nilai signifikansi>0,05 maka model yang paling sesuai adalah random effect dan sebaliknya jika nilai signifikansi<0,05 maka model yang paling sesuai adalah fixed effect. Hasil uji Hausman pada Tabel 3 memperlihatkan nilai signifikansi yang diperoleh 0,0027 kurang dari 0,05 sehingga model yang sesuai adalah model fixed effects.

\section{Uji Asumsi Klasik}

Sebelum melakukan analisis lebih jauh pada model fixed effects yang paling sesuai untuk menganalisis data pada riset ini, terlebih dahulu dilakukan pengujian asumsi klasik. 


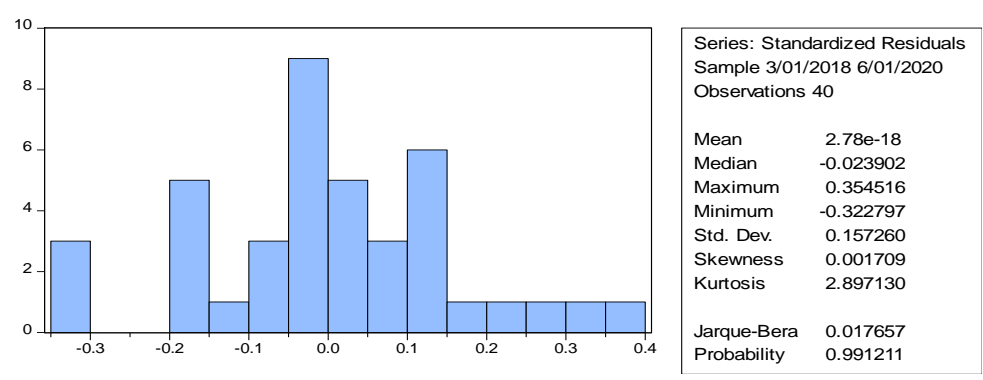

Gambar 1. Hasil Uji Normalitas

Gambar 1 menunjukkan hasil pengujian normalitas. Hasil perhitungan tersebut menunjukkan bahwa nilai jarque-bera $=0,017<5,99$ sehingga residual dalam riset ini berdistribusi normal.

Tabel 4. Korelasi Antar Variabel Bebas

\begin{tabular}{cccc}
\hline & CAR & INFLASI & GDP \\
\hline CAR & 1 & 0,02 & 0,14 \\
\hline INFLASI & 0,02 & 1 & 0,73 \\
\hline GDP & 0,14 & 0,73 & 1 \\
\hline St
\end{tabular}

Sumber: Data diolah (2021)

Tabel 4 menunjukkan besarnya korelasi antar variabel bebas. Untuk menentukan ada tidaknya multikolinieritas pada variabel yang dianalisis dapat dilihat dari nilai korelasi antar variabel bebas. Jika koefisien korelasinya $<0,9$ maka dapat tidak terjadi multikolinieritas. Hasil perhitungan pada Tabel 4 memperlihatkan besarnya korelasi antar variabel bebas berada diantara 0,02 sampai dengan 0,73 yang artinya tidak ada pasangan variabel bebas yang memiliki koefisien korelasi lebih dari 0,9 sehingga tidak terjadi multikolinieritas.

Tabel 5. Hasil Uji Autokorelasi

\begin{tabular}{llll}
\hline F-hitung & 1,540994 & Sig. $F(2,33)$ & 0,2292 \\
\hline Obs* $^{2}$ & 3,331233 & Sig. $\chi^{2}(2)$ & 0,1891 \\
\hline
\end{tabular}

Sumber: Data diolah (2021)

Tabel 6. Hasil Uji Heteroskedatisitas

\begin{tabular}{llll}
\hline F-hitung & 0,870786 & Sig. $\mathrm{F}(3,35)$ & 0,4655 \\
\hline Obs*R ${ }^{2}$ & 2,708737 & Sig. $\chi^{2}(3)$ & 0,4387 \\
\hline Scaled explained SS & 3,746248 & SIg. $\chi^{2}(3)$ & 0,2902
\end{tabular}

Sumber: Data diolah (2021) 
Hasil pengujian autokorelasi pada Tabel 5 dilakukan dengan metode BreuschGodfrey. Dari pengujian tersebut diperoleh nilai sig dari Obs $* \mathrm{R}^{2}$ sebesar 0,1891 sehingga pengujian autokorelasi terpenuhi. Hasil pengujian heteroskedastisitas pada Tabel 6 dilakukan dengan metode Harvey. Dari pengujian tersebut diperoleh nilai sig dari Obs* $\mathrm{R}^{2}$ sebesar 0,4387 sehingga pengujian heteroskedastisitas terpenuhi.

\section{Model Regresi Data Panel}

Tabel 7. Koefisien Model Regresi Data Panel

\begin{tabular}{ccccc}
\hline Variabel & Koefisien & SE & thitung & Sig \\
\hline C & 0,4480 & 0,423 & 1,060 & 0,297 \\
\hline CAR & $-0,0045$ & 0,016 & $-0,285$ & 0,777 \\
\hline INFLASI & $-0,0032$ & 0,098 & $-0,033$ & 0,974 \\
\hline GDP & 0,00055 & 0,023 & 0,024 & 0,981
\end{tabular}

Sumber: Data diolah (2021)

Persamaan model regresi data panel pada Tabel 7 dapat dituliskan sebagai berikut

$$
R O A_{i t}=0,4480-0,0045 \text { CAR }_{i t}-0,0032 \text { Inflasi }_{i t}+0,00055 G D P_{i t}+e_{i t}
$$

a. Konstanta model 0,4480 mengindikasikan bahwa CAR, inflasi, dan GDP yang memiliki nilai 0 mengakibatkan ROA sebesar 0,448 .

b. CAR dengan koefisien $-0,0045$ artinya ketika CAR pada bank ke-i waktu ke-t mengalami kenaikan sebesar 1\% maka ROA pada bank ke-i waktu ke-t mengalami penurunan sebesar $0,0045 \%$ dengan mengasumsikan nilai variabel lainnya tetap. CAR dengan nilai sig $=0,777>0,05$ menunjukkan bahwa CAR tidak berpengaruh pada ROA.

c. Inflasi dengan koefisien $-0,0032$ artinya ketika inflasi pada bank ke-i waktu ke-t mengalami kenaikan sebesar 1\% maka ROA pada bank ke-i waktu ke-t mengalami penurunan sebesar $0,0032 \%$ dengan mengasumsikan nilai variabel lainnya tetap. Inflasi dengan nilai sig $=0,974>0,05$ menunjukkan bahwa inflasi tidak berpengaruh pada ROA.

d. GDP dengan koefisien 0,00055 artinya ketika GDP pada bank ke-i waktu ke-t mengalami kenaikan sebesar 1\% maka ROA pada bank ke-i waktu ke-t mengalami kenaikan sebesar 0,00055\% dengan mengasumsikan nilai variabel lainnya tetap. GDP dengan nilai sig $=0,777>0,05$ menunjukkan bahwa GDP tidak berpengaruh pada ROA. 
Tabel 8. Hasil Uji F

\begin{tabular}{cc}
\hline \multicolumn{2}{c}{ Cross-section fixed (dummy variables) } \\
\hline Sig $\left(\mathrm{F}_{\text {hitung }}\right)$ & 0,000 \\
\hline
\end{tabular}

Sumber: Data diolah (2021)

Hasil uji F pada Tabel 8 menunjukkan nilai sig sebesar 0,000. Berdasarkan hasil ini dapat disimpulkan bahwa CAR, Inflasi, dan GDP berpengaruh simultan terhadap ROA dengan kontribusi sebesar $67,16 \%$.

Tabel 9. Koefisien Model Fixed Effects Tiap Bank

\begin{tabular}{cc}
\hline \multicolumn{2}{c}{ Fixed Effects (Cross) } \\
\hline BRIS & 0,3036 \\
\hline BSB & $-0,2939$ \\
\hline BVS & $-0,1403$ \\
\hline BJBS & 0,1305 \\
\hline \multicolumn{2}{l}{ Sumber: Data diolah } \\
\hline
\end{tabular}

Berdasarkan hasil perhitungan pada Tabel 9 dapat dibuat model regresi untuk masing-masing Bank Umum Syariah berikut:

a. Model regresi untuk Bank BRISyariah

Konstanta model regresi untuk Bank BRI Syariah 0,3036 +0,4480=0,7516 yang mengindikasikan bahwa ketika nilai CAR, Inflasi, dan GDP nol maka ROA Bank BRISyariah sebesar 0,7516. Model yang bersesuaian sebagai berikut $R O A_{t}=0,7516-0,0045$ CAR $_{t}-0,0032$ Inflasi $_{t}+0,00055 G D P_{t}+e_{t}$

b. Model regresi untuk Bank Syariah Bukopin

Konstanta model regresi untuk Bank Syariah Bukopin -0,2939 + 0,4480=0,1541 yang mengindikasikan bahwa ketika nilai CAR, Inflasi, dan GDP nol maka ROA Bank Syariah Bukopin sebesar 0,1541. Model yang bersesuaian sebagai berikut $R O A_{t}=0,1541-0,0045$ CAR $_{t}-0,0032$ Inflasi $_{t}+0,00055 G D P_{t}+e_{t}$

c. Model regresi untuk Bank Victoria Syariah

Konstanta model regresi untuk Bank Victoria Syariah $-0,1403+0,4480=0,3077$ yang mengindikasikan bahwa ketika nilai CAR, Inflasi, dan GDP nol maka ROA Bank Victoria Syariah sebesar 0,3077. Model yang bersesuaian sebagai berikut $R O A_{t}=0,3077-0,0045$ CAR $_{t}-0,0032$ Inflasi $_{t}+0,00055 G D P_{t}+e_{t}$

d. Model regresi untuk Bank Jabar Banten Syariah 
Konstanta model regresi untuk Bank Jabar Banten Syariah 0,1305 + 0,4480=0,5785 yang mengindikasikan bahwa ketika nilai CAR, Inflasi, dan GDP nol maka ROA Bank Jabar Banten Syariah sebesar 0,5785. Model yang bersesuaian sebagai berikut

$$
R O A_{t}=0,5785-0,0045 C_{A} R_{t}-0,0032 \text { Inflasi }_{t}+0,00055 G D P_{t}+e_{t}
$$

Dari keempat persamaan yang dihasilkan diketahui bahwa pada kondisi CAR, Inflasi, dan GDP bernilai 0 Bank BRISyariah memiliki nilai ROA paling tinggi disusul Bank Jabar Banten Syariah pada posisi kedua, Bank Victoria Syariah pada posisi ketiga serta Bank Syariah Bukopin pada posisi terakhir. Hal ini mengindikasikan bahwa dengan kondisi yang sama, Bank BRISyariah dapat menghasilkan keuntungan yang lebih besar dibandingkan dengan bank umum Syariah non devisa lainnya.

\section{Pengaruh CAR, Inflasi, dan GDP terhadap ROA}

Berdasarkan analisis yang dilakukan didapatkan hasil bahwa CAR, inflasi, dan GDP secara parsial tidak berpengaruh pada ROA namun secara simultan CAR, inflasi, dan GDP berpengaruh pada ROA. Hasil ini mengindikasikan bahwa turunnya ROA disebabkan oleh nilai CAR dan inflasi yang tinggi serta turunnya GDP di Indonesia secara Bersama. Hasil temuan ini tidak sejalan dengan riset Mawaddah, Nuril dan Harun dengan temuan hanya inflasi yang memberikan pengaruh pada ROA.

Pengaruh CAR, inflasi,dan GDP secara simultan pada ROA memiliki dampak terhadap berkurangnya kemampuan masyarakat dalam melakukan kegiatan jual beli. Banyak pengusaha maupun perusahaan yang tidak melakukan proses produksi karena permintaan akan barang dan jasa serta permintaan ekspor berkurang yang mengakibatkan perekonomian mengalami hambatan. Perusahaan tidak bersemangat dalam beinvesatasi serta adanya tingkat pengembalian yang mengalami macet atau adanya kredit macet mengakibatkan pendapatan bank menurun sehingga ROA dari bank mengalami penurunan. Bank Umum Syariah harus memiliki kemampuan dalam membaca peluang yang diperoleh dari CAR, inflasi serta GDP secara bersama tanpa mengesampingkan salah satu diantaranya. CAR, inflasi serta GDP mempunyai pengaruh besar pada pendapatan Bank Umum Syariah Non Devisa dan secara langsung memperbaiki kondisi ROA yang mengalami penurunan. 


\section{KESIMPULAN}

CAR, inflasi dan GDP secara parsial tidak berpengaruh pada ROA namun secara simultan CAR, inflasi dan GDP berpengaruh pada ROA. Akan tetapi, Capital Adequacy Ratio, Inflasi dan Gross Domestik Product secara bersama-sama berpengaruh terhadap Return On Assets artinya CAR, inflasi serta GDP mempunyai pengaruh besar pada pendapatan Bank Umum Syariah Non Devisa dan secara langsung memperbaiki kondisi ROA yang mengalami penurunan. Untuk memperoleh hasil riset yang lebih baik diharapkan dilakukan riset lebih mendalam dengan menambahkan beberapa variabel lainnya diluar variabel yang telah diteliti agar diperoleh model ROA yang paling sesuai dengan error yang kecil.

\section{REFERENSI}

Alim, S. (2013). Analisis Pengaruh nflasi Dan Bi Rate Terhadap Return On Assetss (ROA) Bank Syariah Di ndonesia. Jurnal Modernisasi, Volume 3, 205.

Brue, R. M. (1990). Economics:Priciples, Problems and Policies . McGraw: Hill Publishing Company.

Edhi Satriyo Wibowo, M. S. (2013). Analisis Pengaruh Suku Bunga, nflasi, CAR, BOPO, NPF Terhadap Profitabilitas Bank Syariah. Diponegoro Journal Of Management, Volume 2, 2-3.

Harun, U. (2016). Pengaruh Ratio-Ratio Keuangan CAR, LDR, NIM, BOPO, NPL Terhadap ROA. Jurnal Riset Bisnis Dan Manajemen, Volume 1, 71.

Hasibuan, M. S. (2001). Dasar-dasar Perbankan. Jakarta: Bumi Aksara.

Hidayati, A. N. (2014). Pengaruh nflasi, Bi Rate Dan Kurs Terhadap Profitabilitas Bank Syariah Di ndonesia. Jurnal An-Nisbah, Volume 1, 78.

Hidayati, A. N. (2014). Pengaruh nflasi, BI Rate Dan Kurs Terhadap Profitabilitas Bank Syariah Di ndonesia. Jurnal An-Nisbah, Volume 1, 76.

Husna, S. (1998). Manajemen Keuangan - Teori dan Penerapan. Yogyakarta: BPFE.

I Nyoman Sidhi Adiyadnya, L. G. (2017). Pengaruh Variabel Makro ekonomi terhadap Profitabilitas dan Return Saham Pada ndustri Perbankan di BEI. E- Jurnal Ekonomi dan Bisnis Udayana, Volume 8, 2597.

Karim, A. A. (2004). Sejarah Pemikiran Ekonomi slam . Jakarta: Rajawali Pers. Kasmir. (2014). Analisis Laporan Keuangan. Jakarta: Raja Grafindo Persada.

Loraine Pertiwi, L. S. (2019). Faktor Yang Mempengaruhi Profitabilitas Pada Perbankan Yang Terdaftar di BEI. Jurnal Multiparadigma Akuntansi Volume 1, 283.

Mawaddah, N. (2015). Faktor-Faktor Yang Mempengaruhi Profitabilitas Bank Syariah. Jurnal Etikonomi Volume 14, 246.

Rihfenti Ernayani, N. H. (2017). Faktor-Faktor Yang Mempengaruhi Return On Assetss (Studi Pada Bank Umum Syariah Di ndonesia Periode 2011-2016. Prosiding Seminar Nasional Dan Call For Paper Ekonomi Dan Bisnis, 285. 
Santoso, R. T. (1997). Prinsip Dasar Akuntansi Perbankan. Yogyakarta: Penerbit Andi Affset.

Siamat, D. (2005). Manajemen Lembaga Keuangan, Edisi Keempat. Jakarta: BPFE UI. Sinungan, M. (1993). Manajemen Dana Bank. Jakarta: Bumi Aksara.

Sriyana, J. (2014). Metode Regresi Data Panel : Dilengkapi Analisis Kinerja Bank Syariah Di ndonesia. Yogyakarta: EKONOSIA.

Suhardi, G. (2003). Usaha Perbankan dalam Perspektif Hukum. Yogyakarta: Kanisius.

Suryanto, D. (2000). Erni Umi Hasanah da Pengantar Imu Ekonomi Makro . Jakarta: PT Grafindo Persada.

Suted, A. (2012). Hukum Keuangan Negara . Jakarta: Sinar Grafika. 